spends most of his life making decisions (medix is said to be an Etruscan word which originally meant a judge or decisionmaker); yet very few medical schools include anything about decision-making in the curriculum. It is surely strange that the principal activity of the doctor is largely untaught during six years of intensive study and preparation. Here the computer may act as a catalyst, teaching us all more about the way we make decisions and in the Delphic sense helping us to know ourselves, rather than usurping the doctor's traditional role. This, however, depends on the proposition that computer aids to decision-making do produce tangible benefit. Used sensibly and wisely it begins to seem as if they do have a valuable part to play, though we have a long way yet to go. But at long last it looks as if it is worth persevering.

${ }^{1}$ McDonald, C J, Annals of Internal Medicine, 1976, 84, 162.

${ }^{2}$ de Dombal, F T, Proceedings of the Royal Society of London, B, 1973, 184, 433.

${ }^{3}$ Horrocks, J C, et al, in Decision Making and Medical Care, Can Information Science Help?, eds F T de Dombal and F Gremy. Amsterdam, N Holland, 1976.

${ }^{4}$ Gunn, A A, Fournal of the Royal College of Surgeons of Edinburgh, 1976, 21, 170.

5 Barnard, H F, British Medical fournal, 1976, 1, 383.

\section{Risk of pelvic infection associated with intrauterine devices}

Medical opinion has fluctuated considerably over the last 50 years on the risk of pelvic inflammatory disease due to a foreign body in the uterus, and this fear delayed general acceptance of intrauterine devices ${ }^{1}$ (IUDs) until the 1960 s. After reviewing the evidence in 1968 a World Health Organisation technical group ${ }^{2}$ stated that pelvic infection associated with the IUD is not a significant problem: "Following one month after insertion there is no conclusive evidence that the incidence or severity of pelvic inflammatory disease is greater in those women [IUD wearers] than in the general population." Subsequent evidence has shown this oft-repeated summary statement to be too optimistic.

For some time, however, it has been accepted that there is a risk of infection immediately after insertion. In the Population Council's Co-operative Statistical Program $^{3}$ the pelvic infection rates per hundred woman years decreased over time from 7.7 during the first 15 days to 0.9 from the 37 th to the 72nd month of IUD use. Mishell et al, $^{4}$ in a painstaking bacteriological study of IUDs inserted before hysterectomy in 75 women, showed that the endometrial cavity was sterile in all cases if the device (Lippes Loop D) had been in place for more than 30 days. However, all five transfundal endometrial cultures during the first 24 hours after insertion grew bacteria, and the same organism was identified in the endocervical mucus. Mishell et al concluded that insertion results in the mechanical transfer of bacteria to the usually sterile endometrium but that these are eliminated within a maximum of 30 days. Two reports of subsequent bacterial endocarditis ${ }^{56}$ suggest that insertion may also cause bacteraemia.

In the USA infection has been the main cause of serious IUD morbidity and mortality associated with use of IUDs, ${ }^{7} 8$ and the risk appears to be greatest if infection is associated with abortion of a pregnancy with a device in situ. ${ }^{189}$

Two recent retrospective studies ${ }^{1011}$ and one controlled prospective study ${ }^{12}$ have now shown that the incidence of infection unrelated to insertion or pregnancy is also higher in IUD users than in non-users. Targum and Wright ${ }^{10}$ found that $48 \%$ of 50 women with a first attack of acute febrile pelvic infection were currently using an IUD in comparison with $9 \%$ of controls matched for age, marital status, and interval since last pregnancy. Similarly, 38\% of 50 febrile cases in a study by Faulkner and Ory ${ }^{11}$ had been fitted with an IUD compared with $11 \%$ of 200 controls. In this series cases and controls were identified in the emergency room of the principal hospital serving the city of Atlanta, USA. Compared with non-users, IUD users were estimated to have about five times the risk of contracting pelvic infection and this finding was not substantially altered by standardisation for race, education, marital status, past diagnosis of pelvic infection, parity, outcome of last pregnancy, length of contraceptive use, or frequency of sexual intercourse and number of partners. Apparently both cases and controls had a similar risk of coitally acquired pelvic infection, and IUDs did not seem to have been used selectively by women at higher risk of the condition.

Both these studies were of socially disadvantaged, mostly black women, with a very high incidence of pelvic infection. In the report ${ }^{11}$ from Atlanta $58 \%$ of the (febrile) cases and $43.5 \%$ of the controls had had at least one previous attack. However, a large prospective study from Britain of women who might be expected to have a far lower incidence of infection has confirmed the excess risk in IUD users. ${ }^{12}$ Vessey et al have studied 17032 women from 17 Family Planning Association clinics over a number of years, with a drop-out rate for all reasons combined of less than $1 \%$ per annum. Initially $56 \%$ of the women were using oral contraceptives, 19\% (almost all multipara) were using various types of IUD, and $25 \%$ were using the diaphragm. During follow-up hospital admission rates per 100000 women per annum for first attacks of pelvic infection were estimated to be 202 for IUD users and 57 for women using other contraceptive methods.

Does this relative excess of clinical (and perhaps subclinical) infection among IUD users lead to a relative impairment of their subsequent fertility? Preliminary and reassuring data have been provided by Vessey's study, ${ }^{12}$ in which 181 women, all parous, had their IUDs removed for a planned pregnancy. The proportion of women delivering a viable infant within 18 months was nearly identical with that in women whose last contraceptive method had been a diaphragm. Nevertheless, all these women had proved their fertility previously, and the incidence of pelvic infection was so low that a real impairment of fertility due to the IUD in a small subgroup could well have been masked. A controlled prospective study of the fertility of adequate numbers of nulliparous women is now required, preferably including a substantial proportion (of both pastusers and non-users of IUDs) with a previous diagnosis of pelvic infection.

Another variable which needs further study is the influence of the type of IUD. Fiscina et $a^{13}$ have provided some evidence that copper ions inhibit the growth of gonococci in vitro. Their suggestion that the new generation of copperbearing IUDs might protect against infection has not yet been clinically confirmed.

The risk of infection (in common with other hazards of contraception) must be balanced against risks inherent in other methods. Pelvic infection seems to be about four or five times more likely among IUD users than other women, and this is the main cause of mortality and morbidity from the method. However, the US Food and Drug Administration has estima- 
$\operatorname{ted}^{18}$ that the mortality rate from the IUD is between one and ten deaths per million woman years, while with oral contraceptives it is 22 to 45 per million woman years. Admission rates to hospital with IUDs are similar to those with oral contraceptives -0.3 to 1.0 per hundred woman years of use. For each potential IUD user, the risks and benefits of the method must be balanced against those of the alternatives and of pregnancy. As the hazards of combined oral contraceptives increase with advancing age (14-16 $^{10 D s}$ may be preferable for older women. In contrast, the risk of subsequent infertility indicates extra care in recommending the method for younger women of low or zero parity-and extra vigour in the treatment of actual infection.

${ }^{1}$ Huber, S, et al, Population Report, Department of Medical and Public Affairs, George Washington University Medical Center, 1975, Series B, No $2,21$.

2 World Health Organisation, Intrauterine Devices: Physiological and Clinical Aspects, Technical Report Series. No 397, Geneva, WHO, 1968.

3 Tietze, C, and Lewit, S, Studies in Family Planning, 1970, 55, 1.

4 Mishell, D R, et al, American fournal of Obstetrics and Gynecology, 1966, 96, 119.

${ }^{5}$ Cobbs, C G, Annals of Internal Medicine, 1973, 78, 451.

6 de Swiet, M, Ramsay, I D, and Rees, G M, British Medical fournal, 1975, 3, 76 .

${ }^{7}$ Scott, R B, Obstetrics and Gynecology, 1968, 31, 322.

${ }^{8}$ Jennings, J, Report of Safety and Efficacy of Dalkon Shield and Other IUDs: Obstetric-Gynecology Advisory Committee (to the US Food and Drug Administration) October 1974. Quoted in Population Report, Department of Medical and Public Affairs, George Washington University Medical Center, 1975, Series B, No 2.

${ }^{9}$ Eisinger, S H, American fournal of Obstetrics and Gynecology, 1976, 124, 393.

10 Targum, S D, and Wright, N H, American fournal of Epidemiology, 1974, 100,262 .

11 Faulkner, W L, and Ory, $\mathrm{H}$ W, fournal of the American Medical Association, 1976, 235, 1851.

12 Vessey, M P, et al, fournal of Biosocial Science, 1976, in press.

${ }^{13}$ Fiscina, B, et al, American fournal of Obstetrics and Gynecology, 1973, 116, 86.

14 Inman, W H W, and Vessey, M P, British Medical fournal, 1968, 2, 193.

15 Mann, J I, et al, British Medical fournal, 1975, 2, 241.

16 Mann, J I, and Inman, W H W, British Medical fournal, 1975, 2, 245.

\section{Primary pulmonary hypertension}

Pulmonary hypertension is a common complication of diseases of the heart or lungs, being either of postcapillary origin and complicating mitral valve disease, left ventricular failure, or rarely pulmonary veno-occlusive disease ${ }^{1}$ or precapillary in origin as in hypoxic lung disease, thromboembolism, chronic altitude hypoxia, or congenital septal defects with the Eisenmenger reaction. In a small group of patients (who are usually young women, though some children are affected) pulmonary hypertension arises with no demonstrable cause. The nature of this idiopathic or primary pulmonary hypertension remains an enigma. ${ }^{2-6}$

Pulmonary hypertension may result from thromboembolism, ${ }^{7}$ and the diagnosis of silent thromboembolism affecting the smaller vessels can, indeed, be very difficult in life, while assessing its causative role at necropsy can be equally perplexing. Goodwin et $a l^{8}$ reported eight cases of pulmonary hypertension with no clinical evidence of thromboembolism, but three of the four cases examined post mortem had thrombi in the smaller arteries. However, in 23 cases of pulmonary hypertension reported by Walcott et $a l^{5}$ only 10 showed evidence of thromboembolic changes, and this they considered a complicating rather than an initiating feature. Morphological studies in 156 cases with a clinical diagnosis of primary pulmonary hypertension showed no evidence of thromboembolism in over $70 \%{ }^{6}$ The pathological changes were identical to those found in cases of congenital heart disease complicated by pulmonary hypertension, with medial hypertrophy and laminar intimal arteriolar fibrosis suggesting a vasoconstrictive aetiology. Anderson et $a l^{9}$ showed a reduction in the total number of small non-muscular arteries, with intimal thickening and loss of luminal area in those that remained.

About one-third of cases of primary pulmonary hypertension are associated with Raynaud's disease, scleroderma, or another "collagen" disease, which might suggest that immunological factors may play a part. Drugs have also been implicated as a cause, the increase in pulmonary hypertension in Europe in the period 1968-70 being closely related to the introduction of the anorectic agent aminorex fumarate. ${ }^{10}$ Recently Kleiger et al $^{11}$ reported six patients with severe pulmonary hypertension who had taken oral contraceptives. Three of the cases had predisposing factors: one had mild pulmonary hypertension since the closure of a ductus arteriosus, one had systemic lupus erythematosus, and a third had a family history of primary pulmonary hypertension. In the other three cases there was no history of findings suggestive of a predisposing cause. Oakley and Somerville ${ }^{12}$ have previously reported three patients with congenital heart disease and leftto-right shunts in whom shunt reversal and severe pulmonary hypertension developed within six months to two years of the start of oral contraception. Walcott $e t a l^{5}$ also noted the adverse effect of pregnancy on pulmonary hypertension. In some cases at least it seems that female reproductive steroids may trigger off a progressive vascular response, particularly where there is a predisposing lesion.

The clinical features are of increasing dyspnoea, ankle swelling, and sometimes syncopal attacks. Some patients complain of a dull retrosternal chest pain on exercise. About one-third of patients give a history of Raynaud's disease or of arthritis. The most constant physical finding is of increased intensity of the pulmonary component of the second heart sound, which is often palpable. Systolic murmurs are commonly heard, and in patients with severe pulmonary hypertension a pulmonary diastolic murmur may develop. Signs of right heart failure may be prominent. The electrocardiogram shows right axis deviation and right ventricular hypertrophy, while the chest radiograph may only show prominence of the main pulmonary artery segment. Cardiac catheterisation confirms the presence of pulmonary hypertension, but the pulmonary arterial wedge pressure is normal. ${ }^{5}$

The clinical course is progressive and usually fatal in two to eight years. A few patients live longer, and Wagenvoort and Wagenvoort ${ }^{6}$ reported four out of 110 patients in whom symptoms had been present and between 20-29 years before death; but regression of the disease has not been recorded. A faint glimmer of hope is therefore raised by the report by Bourdillon and Oakley ${ }^{13}$ of a 10 -year-old girl who presented with fainting attacks and was found to have primary pulmonary hypertension. There seemed to be progressive deterioration until 16 years of age, when she began to feel better and the signs of severe pulmonary hypertension began to regress. By the age of 19 she had become virtually asymptomatic and led a normal active life; her mean pulmonary arterial pressure, which had been $80 \mathrm{~mm} \mathrm{Hg}$ at age 11, had by then fallen to $24 \mathrm{~mm} \mathrm{Hg}$.

Unfortunately there seems to be no ready explanation for this regression. The girl was given anticoagulants in the belief that they would prevent secondary pulmonary arterial thrombosis as a complication of the disease. However, anticoagulants 